\title{
The fracture load and failure types of veneered anterior zirconia crowns: An analysis of normal and Weibull distribution of complete and censored data.
}

\author{
Stawarczyk, Bogna ; Özcan, Mutlu ; Hämmerle, Christoph H F ; Roos, Malgorzata
}

\begin{abstract}
OBJECTIVES: The aim of this study was to compare the fracture load of veneered anterior zirconia crowns using normal and Weibull distribution of complete and censored data. METHODS: Standardized zirconia frameworks for maxillary canines were milled using a CAD/CAM system and randomly divided into 3 groups ( $\mathrm{N}=90, \mathrm{n}=30$ per group). They were veneered with three veneering ceramics, namely GC Initial ZR, Vita VM9, IPS e.max Ceram using layering technique. The crowns were cemented with glass ionomer cement on metal abutments. The specimens were then loaded to fracture $(1 \mathrm{~mm} / \mathrm{min})$ in a Universal Testing Machine. The data were analyzed using classical method (normal data distribution $(\mu, \sigma)$; Levene test and one-way ANOVA) and according to the Weibull statistics (s, $\mathrm{m}$ ). In addition, fracture load results were analyzed depending on complete and censored failure types (only chipping vs. total fracture together with chipping). RESULTS: When computed with complete data, significantly higher mean fracture loads $(\mathrm{N})$ were observed for GC Initial ZR $(\mu=978, \sigma=157$; $\mathrm{s}=1043, \mathrm{~m}=7.2)$ and VITA VM9 $(\mu=1074, \sigma=179 ; \mathrm{s}=1139 ; \mathrm{m}=7.8)$ than that of IPS e.max Ceram $(\mu=798, \sigma=174$; $\mathrm{s}=859, \mathrm{~m}=5.8)(\mathrm{p}<0.05)$ by classical and Weibull statistics, respectively. When the data were censored for only total fracture, IPS e.max Ceram presented the lowest fracture load for chipping with both classical distribution $(\mu=790, \sigma=160)$ and Weibull statistics $(s=836, m=6.5)$. When total fracture with chipping (classical distribution) was considered as failure, IPS e.max Ceram did not show significant fracture load for total fracture $(\mu=1054$, $\sigma=110$ ) compared to other groups (GC Initial ZR: $\mu=1039, \sigma=152$, VITA VM9: $\mu=1170, \sigma=166$ ). According to Weibull distributed data, VITA VM9 showed significantly higher fracture load $(\mathrm{s}=1228, \mathrm{~m}=9.4)$ than those of other groups. SIGNIFICANCE: Both classical distribution and Weibull statistics for complete data yielded similar outcomes. Censored data analysis of all ceramic systems based on failure types is essential and brings additional information regarding the susceptibility to chipping or total fracture.
\end{abstract}

DOI: https://doi.org/10.1016/j.dental.2011.11.023

Posted at the Zurich Open Repository and Archive, University of Zurich ZORA URL: https://doi.org/10.5167/uzh-56996

Journal Article

Accepted Version

Originally published at:

Stawarczyk, Bogna; Ȯzcan, Mutlu; Hämmerle, Christoph H F; Roos, Malgorzata (2012). The fracture load and failure types of veneered anterior zirconia crowns: An analysis of normal and Weibull distribution of complete and censored data. Dental Materials, 28(5):478-487.

DOI: https://doi.org/10.1016/j.dental.2011.11.023 
The fracture load and failure types of veneered anterior zirconia crowns:

\section{An analysis of normal and Weibull distribution of complete and censored data}

\section{Abstract}

Objectives: The aim of this study was to compare the fracture load of veneered anterior zirconia crowns using normal and Weibull distribution of complete and censored data. Methods: Standardized zirconia frameworks for maxillary canines were milled using a CAD/CAM system and randomly divided into 3 groups $(\mathrm{N}=90, \mathrm{n}=30$ per group). They were veneered with three veneering ceramics, namely GC Initial ZR, Vita VM9, IPS e.max Ceram using layering technique. The crowns were cemented using glass-ionomer cement on metal abutments. The specimens were then loaded to fracture $(1 \mathrm{~mm} / \mathrm{min})$ in a Universal Testing Machine. The data were analyzed using classical method (normal data distribution $(\mu, \sigma)$; Levene test followed by one-way ANOVA) and according to the Weibull statistics $(s, m)$. In addition, fracture load results were analyzed depending on complete and censored failure types (only chipping vs. total fracture together with chipping). Results: When computed with complete data, significantly higher mean fracture loads $(N)$ were observed for GC Initial $Z R(\mu=978, \sigma=157 ; s=1043, m=7.2)$ and VITA VM9 $(\mu=1074, \sigma=179 ; s=1139 ; m=7.8)$ than that of IPS e.max Ceram $(\mu=798$, $\sigma=174 ; s=859, m=5.8)(p<0.05)$ by classical and Weibull statistics, respectively. When the data were censored for only total fracture, IPS e.max Ceram presented the lowest fracture load for chipping with both classical distribution $(\mu=790, \sigma=160)$ and Weibull statistics $(s=836, m=6.5)$. When total fracture with chipping (classical distribution) was considered as failure, IPS e.max Ceram did not show significant fracture load for total fracture $(\mu=1054, \sigma=110)$ compared to other groups (GC Initial ZR: $\mu=1039, \sigma=152$, 
VITA VM9: $\mu=1170, \sigma=166)$. According to Weibull distributed data, VITA VM9 showed significantly higher fracture load $(s=1228, m=9.4)$ than those of other groups. Conclusion: Both classical distribution and Weibull statistics for complete data yielded similar outcomes. Censored data analysis of all ceramic systems based on failure types is essential and brings additional information regarding the susceptibility to chipping or total fracture.

Keyword: censored data, chipping, fracture load, normal distribution, Weibull statistics, zirconia 


\section{Introduction}

Zirconia reconstructions substitute the metal-ceramic fixed-dental prosthesis (FDP) due to their high biocompatibility [1] and comparable mechanical properties with metalceramics [2,3]. Several in vitro studies reported that zirconia seems to provide the desired long-term stability for clinical applications $[4,5]$ and this was also confirmed in clinical studies [6-11]. Zirconia seldom fractures, due to its high flexural strength with $1000 \mathrm{MPa}[10,12]$ that surpasses the flexural strength of the veneering ceramics $(50-$ $120 \mathrm{MPa}$ ) [13]. Confirming this information, chipping of the veneering ceramic is often reported in clinical studies [6-11]. The stability of the complete system consisting the zirconia framework and the veneering ceramic is of clinical importance that could be tested with the Voss test [14]. In this kind of test, the anatomy of the crowns is not excluded and therefore could better represent the clinical conditions compared to standard tests where geometrical specimens with standard dimensions are used. The restoration is cemented on the metal abutments, and force is applied to the crowns simulating the antagonist load. The Voss test was originally developed to test the fracture load of metal-ceramic FDPs [14] but it is also being applied for zirconia FDPs $[4,5]$.

The obtained fracture load results could be statistically analyzed with different methods. The common approach using the classical method assumes normal distribution and uses analysis of variance (ANOVA) followed by a post-hoc test. More recently, the Weibull statistic was also used for facture load analysis of FDPs [15]. The Weibull statistics in the dental materials research provides information on the reliability of zirconia [16]. The fracture load data of zirconia FDPs could also be censored 
considering the failure types (chipping vs. total fracture) [4]. Censoring could not be practiced in metal-ceramic FDPs since the alloys often do not fracture due to their ductility [17].

Therefore, the objective of this present study was to compare the fracture load results of veneered zirconia crowns and analyze the results with both classical method (assumption of normal distribution) and the Weibull statistics (complete vs. censored) considering chipping and total fracture. The primary hypothesis was to test whether the fracture load results (complete and censored data) analyzed with the classical method yields similar results compared to Weibull statistics. The secondary hypothesis was to test whether the censoring of data with respect to failure types (chipping and total fracture) under classical distribution and Weibull statistics give similar information in term of significant differences between fracture load results of all-ceramic systems. 


\section{Material and Methods}

\subsection{Specimen preparation}

Standardized zirconia frameworks were prepared using a metal abutment analog in the shape of an anatomically prepared maxillary canine with a chamfer preparation of $1 \mathrm{~mm}$. They were cast from a CoCr alloy (Wironium plus, Bego, Bremen, Germany) and scanned (3Shape D 250, Wieland Dental, Pforzheim, Germany). An anatomically supported zirconia framework was constructed (ZENO TEC, Wieland Dental), milled (ZENO 4030 M1, Wieland Dental) in the white state (ZENO TEC Zr Bridge, Wieland Dental) and densely sintered according to the manufacturer's instructions (ZENO TEC Fire, Wieland Dental).

The zirconia frameworks were randomly divided into three groups $(\mathrm{N}=90, \mathrm{n}=30$ per group) and veneered with three layering ceramics: GC Initial ZR, Vita VM9 and IPS e.max Ceram (Table 1). The firing schedule took place in one ceramic oven (D4, Dekema, Freilassing, Germany) strictly following the instructions of each ceramic manufacturer (Table 2). After liner application, veneering ceramic for dentin was applied using a silicone key to achieve a standardized shape and size of the veneers. A second dentin firing was performed after adding a new layer of ceramic to compensate for the shrinkage due to sintering process. Prior to the second firing, the slurry was condensed into the mould with a vibrator for $2 \mathrm{~s}$ at $50 \mathrm{~Hz}$ (Elektro Vibrator Porex, Renfert, Hilzingen, Germany). After the final firing, the veneering ceramic was glazed and the restoration was finished.

The crowns were cemented with glass ionomer cement (KetacCem, 3M ESPE, Seefeld, Germany) on their corresponding metal abutments. During cementation, they 
were secured with finger pressure for 2 minutes. After 10 minutes, the specimens were subjected to loading.

\subsection{Fracture load measurement}

The cemented specimens were loaded in the Universal Testing Machine (Zwick/Roell Z010, Zwick, Ulm, Germany). The load was induced with a flat loading cell on the palatinal surface of the incisal edge at an angle of 45 degrees to the long axis of the tooth at a crosshead speed of $1 \mathrm{~mm} / \mathrm{min}$ [14]. In order to avoid force peaks, a piece of a $0.5 \mathrm{~mm}$ tin foil (Dentaurum, Ispringen, Germany) was placed between the incisal edge and the loading jig. The measurement was stopped as soon as the maximum fracture load decreased by $10 \%$.

The failure types after fracture tests were classified as follows: a) chipping of the veneering ceramic or b) total fracture of zirconia framework together with veneering ceramic (Fig. 1). Failure types were observed under the optical microscope (M3M, Wild, Heerbrugg, Switzerland) at 25x magnification by two operators.

\subsection{Statistical analysis}

The analysis was performed in MINITAB Version 14 (MINITAB, State College, PA, USA). Results of the statistical analysis with p-values smaller than $5 \%$ were considered to be statistically significant.

The Anderson-Darling test for normality and the adjusted Anderson-Darling goodness-of-fit estimates based on the Normal and Weibull distributions were computed for complete and censored data to determine the better fit.

Classical method (assumption of normal distribution) 
The classical analyzing method involves the assumption of the normal distribution of the data. Normal distributed data is based on the Normal (Gaussian) density, defined as follows:

$$
f(x)=\frac{1}{\sqrt{2 \pi} \sigma} \exp \left\{-\frac{(x-\mu)^{2}}{2 \sigma^{2}}\right\}
$$

The Normal distribution has two parameters: the mean $(\mu)$ and the standard deviation $(\sigma)$. The first parameter $(\mu)$ gives the information about the centre of the distribution. The second parameter $(\sigma)$ gives the information about its spread. The Normal distribution is symmetric around the mean [18].

The descriptive statistics (mean, standard deviation (SD), minimum, median, maximum) computed and boxplots were made. Then, the Levene test was applied to disclose the differences in the dispersion of the fracture load between the three different veneered ceramic systems. One-way ANOVA followed by Tukey post-hoc test was applied to disclose the differences in fracture load between all test groups.

\section{Weibull statistics}

The Weibull distribution has two parameters: a) scale or characteristic value (s) and b) shape or Weibull modulus $(\mathrm{m})$ [18]. There are at least five different parameters of the Weibull distribution used in the literature [19]. Frequently, the Weibull statistic applied is based on one particular formulation where the cumulative distribution function is equal to $[16,20]:$ 
$G(x)=1-\exp \left\{-\left(\frac{x-s_{0}}{s}\right)^{m}\right\}$

where for $\mathrm{s}_{0}=0$

$g(x)=\frac{m}{s}\left(\frac{x}{s}\right)^{m-1} \exp \left\{-\left(\frac{x}{s}\right)^{m}\right\}$

is the Weibull density function.

Fig. 2 demonstrates the densities of the Weibull $g(x)(m=8, s=1000)$ and the corresponding Normal distribution $f(x)$ that have equal expectations and equal variances. The density of the Normal distribution was symmetric whereas the density of the Weibull distribution was slightly skewed. In general the Weibull density is symmetric only for $m=3.4$. Whereas for $m<3.4$ and $m>3.4$ it is skewed to the right and to the left, respectively. Note that the scale or characteristic value (s) for Weibull is the fracture load at which $63.2 \%$ of the units fail. Due to the symmetry of the Normal distribution the area under the density for fracture load that is smaller than $\mu$ is equal to $50 \%$ [21].

Failure type analysis (Complete data vs. censored data)

The frequency of the failure types (chipping of the veneering ceramic and total fracture of veneering ceramic together with zirconia framework) in each test group together with their relative frequencies and the corresponding 95\% confidence intervals $(\mathrm{Cl})$ were computed [22].

The failure type analysis included the complete data (all failure types) and censored data by chipping or total fracture [23]. The reliability analysis for fracture load 
under the assumption of Normal and Weibull sampling distributions was performed for complete and censored data. The parameters of the Normal and the Weibull distribution in each test group for fracture load and $95 \% \mathrm{Cl}$ were estimated by least squares. Equal shape (standard deviation) and equal scale (mean) Bartlett's modified likelihood ratio tests together with the appropriate Bonferroni post-hoc confidence interval were conducted. Probability plots were computed. 


\section{Results}

The adjusted Anderson-Darling goodness-of-fit estimates in each group disclosed that there was no clear preference for the assumed Normal or Weibull sampling distribution (Table 3).

Classical method

According to the Levene test $(p=0.734)$, there was no evidence that the dispersions of the distributions between test groups were different. One-way ANOVA $(p<0.001)$ followed by Turkeys' post-hoc indicated that the fracture load of IPS e.max Ceram was lower than those of GC Initial ZR and VITA VM9 (Table 4, Fig. 3). No significant difference was found in the fracture load between GC Initial ZR and VITA VM9.

\section{Weibull statistic}

The test for equal shape parameters $(p=0.13)$ indicated that there was no statistical evidence that the Weibull shape parameters differ between the test groups (Table 4). The test for equal scale parameters $(p<0.001)$ together with the Bonferroni post-hoc confidence interval indicated that IPS e.max Ceram has the smallest scale parameter that differs from the scale parameters of GC Initial ZR and VITA VM9. According to Weibull statistics, no significant difference between scale parameters of GC Initial ZR and VITA VM9 were found.

Failure type analysis (censored data)

It was noted that GC Initial ZR and VITA VM9 failure type distributions were better estimated than total fracture load yielding to chipping. Overall, 19 total fracture and only 
11 chipping incidences were experienced in both GC Initial ZR and VITA VM9 groups. IPS e.max Ceram with chipping failure type was better estimated than fracture load for chipping $(n=24)$ than total fracture $(n=6)($ Table 4$)$.

Total fracture (data censored for chipping)

According to the analysis with the classical method, there was no significant difference in the standard deviations of the total fracture load $(p=0.635)$ (Table 6, Fig. 4). VITA VM9 showed significantly higher mean fracture load than that of GC Initial ZR $(p=0.016)$. However, there was no evidence that IPS e.max Ceram differs statistically from GC Initial ZR and VITA VM9 with respect to the fracture load resulting in total fracture.

When Weibull shape parameters were considered, no significant difference were found between the test groups $(p=0.441)$ (Table 6, Fig. 4). VITA VM9 showed significantly higher scale parameter than those of GC Initial and IPS e.max Ceram $(p=0.002)$. With respect to the Weibull scale parameter, no difference was found between GC Initial and IPS e.max Ceram.

\section{Chipping (data censored for total fracture)}

The results according to the analysis of classical method showed no significant difference between the standard deviations $(p=0.266)$ of all groups. In this analysis, IPS e.max Ceram showed significantly lower mean fracture load than those of GC Initial ZR and VITA VM9 $(p<0.001)$. However, there was no evidence that GC Initial ZR differs from VITA VM9 with respect to the fracture load for chipping (Table 6, Fig. 4).

No significant differences $(p=0.083)$ were observed in Weibull shape parameters between the test groups. IPS e.max Ceram had the scale parameter for fracture load for 
chipping that was lower than those of GC Initial ZR and VITA VM9 $(p<0.001)$. Weibull scale parameter presented no significant difference between GC Initial ZR and VITA VM9 (Table 6, Fig. 4).

Table 7 demonstrates the summary of the results for all normal and Weibull distribution for complete and censored data for each ceramic system. 


\section{Discussion}

In this study, the lognormal distributional assumption could have been considered for the analysis of the data at hand [21]. We did not use this distributional assumption in the present work as the Anderson-Darling goodness-of-fit estimates under complete data assumption suggested different optimal fitting distribution in each group (GC Initial ZR: Weibull $A D=0.705$, VITA VM 9: 3 parameter log-logistic $A D=0.621$, IPS e.max Ceram: lognormal $A D=0.934)$. As it was not clear which distributional assumption was the best one for all three groups at the same time, we decided to concentrate on the assumptions which were well known and frequently used in the literature: namely, the normal and Weibull distributions. We aimed for a concise and an easy understandable presentation of the argument dealing with the censoring for both different fracture types in the studies all-ceramic systems. Therefore, this study compared the fracture load results of zirconia frameworks veneered with three types of glass ceramics and analyzed the results with classical method (assumption of normal distribution) and the Weibull statistics. The analysis was achieved using the complete and censored data considering the failure types of chipping and total fracture.

There was a correspondence between the parameters of the normal and Weibull distribution [23]. The shape $(\mathrm{m})$ of the Weibull distribution governs mostly the spread of the distribution and the scale parameter (s) that influences mostly the expectation. While the shape of the Weibull distribution is inversely proportional to the spread $(\sigma)$ of the normal distribution, the scale parameter of the Weibull distribution corresponds to the mean $(\mu)$ of the normal distribution. Small shape $(m)$ represents a large degree of scatter in the distribution (material is unreliable), whereas large modulus "m" represents 
a small degree of spread (material is reliable). If there are differences in the spread of the fracture load between the groups then one expects to obtain statistically different Weibull shape parameters (Weibull modulus). When the Weibull distribution is assumed, if there are differences in mean fracture load between test groups, one could expect statistically different estimates of the scale parameters.

In analyzing the data, it is very difficult to discriminate between both sampling assumptions. This problem is most pronounced for small sample sizes. The AndersonDarling goodness-of-fit estimate can help to decide which sampling distribution is supported by the measured fracture load in each tested group. Smaller value of the adjusted Anderson-Darling goodness-of-fit estimate indicates a better fit to the data provided by the assumed sampling distribution. In this study, the adjusted AndersonDarling goodness-of-fit estimates in each group disclosed that there was no clear preference for the assumed normal or Weibull sampling distribution. This could be explained by the number of specimens used ( $n=30$ per group). In such a case the true modulus of the Weibull distribution in each test group is estimated within a factor of 1.46 with $95 \%$ probability under complete data assumption [24].

Under "complete data assumption", one could postulate that the measured fracture load is the load of interest and all failure modes are considered as one failure type. Also, in "normal distribution", there are classical tools for the statistical analysis such as Levene test that is used to disclose the heterogeneity of the variance between the experimental groups. On the other hand, one-way ANOVA discloses the differences in the mean fracture load of crowns between groups under homogeneity of distribution. High sample mean $(\mu)$ indicates a high mean fracture load but small estimate of 
standard deviation $(\sigma)$ indicates that the distribution has small spread and the material has a higher structural reliability.

The findings provided by the "Weibull analysis" correspond to the findings provided by the analysis under normal distribution. In this analysis, high estimate of "s" indicates high mean fracture load. High estimate of " $m$ " indicates that the spread of the distribution is small and the material has higher structural reliability.

In this study, no differences were found in the distributions of data between the tested groups; test for equal standard deviation and test for equal shape parameters were not significant. Therefore, it can be stated that all material combinations have similar structural reliability. With both normal and Weibull distribution (complete data assumption), GC Initial ZR and VITA VM9 showed statistically higher fracture loads than IPS e.max Ceram; test for equal means significant, test for equal scale parameters were significant. Thus, the results provided under the normal and Weibull assumptions for complete data could be considered comparable.

The conclusions under complete data assumption differ from the findings for the two failure modes analysis. When adjusting for censoring IPS e.max Ceram presented the lowest fracture load for failure type chipping under both distributional assumptions. With censored data by total fracture, IPS e.max Ceram showed similar fracture load under normal distribution and a significant lower fracture load than VITA VM9 under Weibull distribution. The results and conclusions with respect to IPS e.max Ceram which were obtained under the Normal and Weibull assumptions for two separate failure types (chipping and total fracture) are slightly different for total fracture but similar for chipping. 
Under "censored data assumption", the measurements provide the individual failure incidences either in the form of total fracture with chipping or chipping alone, under fracture load. However, failures originate from two independent flaw populations. Chipping of the veneering ceramic is of surface flaw origin and total fracture of veneering ceramic together with zirconia framework at the same time, is of volume flaw origin. The International Standardization Organization (ISO 20501) suggested one method for the analysis of two concurrent failure types [25]. Even though the information on the distribution of the one failure type is of interest, all other failure modes are incorporated in the analysis and considered as censored data.

When chipping together with total fracture of the framework is of primary interest, certain crowns may not have reached the endpoint of interest. This is due to the fact that the loading in the Universal Testing Machine was stopped on purpose as soon as the maximum fracture load decreased by $10 \%$. Consequently, the exact survival times until total fracture load are not known for such crowns. The survival times of specimens with total fracture is right-censored. When there is censoring, the arithmetic mean of the fracture load for total failures is underestimated, and when the censoring is substantial this underestimate is higher. The censoring indicator is used to designate which fracture loads result in which failure type of interest. In that respect, censoring makes the analysis more complicated since the censored individuals provide some information especially when framework was still intact at the time point of chipping.

For chipping only, according to normal distribution and Weibull distribution zirconia crowns veneered with the layering ceramic IPS e.max Ceram showed significantly lower fracture load compared to the other groups. On the other hand, the 
total fracture load of crowns veneered with IPS e.max Ceram was similar with GC Initial ZR. The zirconia crowns veneered with Vita VM9 showed chipping under higher loads and total fracture with chipping compared with to those of other groups. Several in-vitro studies suggest the use of zirconia for both the anterior and posterior FDPs with high initial flexural strength above $1000 \mathrm{MPa}[2,4,12]$. However, a superior mechanical strength of the framework itself is not the only prerequisite for long-term clinical success. Clinical failures of zirconia FDPs often occur due to chipping of the veneering ceramic [6-11]. Depending on the manufacturer, the flexural strength of the veneering ceramics range between 70 and $100 \mathrm{MPa}$ [13]. This indicates that the weakest part of zirconia FDPs is still the veneering ceramics themselves.

When total fractures together with chipping is considered, according to the normal distribution, VITA VM9 showed the highest results being not significant than that of IPS e.max Ceram. According to the Weibull distribution however, VITA VM9 presented significantly higher fracture load than those of the other groups.

Overall, the results of this study and the comparison of the statistical methods (normal vs. Weibull) showed slight differences between the materials in the censored data. Future studies testing mechanical properties of bilayered ceramics should define the failure types for the statistical methods in order to discriminate the statistical differences between material combinations.

The main focus of this study was the use of normal and Weibull distribution with complete and censored data for static tests. The fatigue of tested groups was not considered in this study. Certainly fatigue aspect is often the clinical phenomena particularly in aged restorations [26-29]. Further studies should investigate the aging of 
all-ceramic systems and compare the data with the findings of this study. It is indeed true that the available clinical studies show very rare framework fractures. However, the results derived from static loading tests can be considered extremely high values that possibly occur seldom in the oral environment. This is in fact an inherent concern of all in vitro test methods. Perhaps not the fracture load but the failure types and especially chipping types observed in this study should be coupled with the clinical observations. Since such failures are observed not necessary as a consequence of aging clinically. Knowing the origin of the failure does not affect the end results, which is the total fracture or chipping that is observed clinically. Our objective here was rather to look at the effect of data censoring that may affect the decimation of fracture load of all-ceramic systems in in-vitro studies. 


\section{Conclusion}

Based on the findings of this study, the following could be concluded:

1. The differences between the Normal and Weibull distribution were minor for the tested ceramic assemblies.

2. Failure types of chipping alone and framework fracture together with chipping are essential to consider separately for censoring the data as they bring additional important information regarding the susceptibility of the bilayared ceramic systems to such failure types.

\section{Acknowledgement}

The authors would like to thank Wieland Dental, GC Europe, Vita Zahnfabrik and Ivoclar Vivadent for supporting this study with materials and to Dirk Jahn (nt-trading, Neustadt an der Weinstrasse, Germany) for fabricating all zirconia frameworks. We are grateful to Martina A. Schmid for the support in writing the manuscript. 


\section{References:}

1. Piconi C, Maccauro G. Zirconia as a ceramic biomaterial. Biomaterials 1999;20:125.

2. Sturzenegger $B$, Fehér $A$, Lüthy $H$, Schärer $P$, Gauckler LJ. Reliability and strength of all-ceramic dental restorations fabricated by direct ceramic machining (DCM). Int J Comp Dent 2001;4:89-106.

3. Lüthy H, Filser F, Loeffel $O$, Schumacher M, Gauckler LJ, Hämmerle CHF. Strength and reliability of four unit all-ceramic posterior bridges. Dent Mater 2005;21:930-937.

4. Fischer J, Stawarczyk B. Compatibility of machined Ce-TZP/Al2O3 nanocomposite and a veneering ceramic. Dent Mater 2007;23:1500-1505.

5. Fischer J, Stawarczyk B, Trottmann A, Hämmerle CHF. Impact of thermal properties of veneering ceramics on the fracture load of layered Ce-TZP/A nanocomposite frameworks. Dental Mater 2009;25:326-330.

6. Vult von Steyern PV, Carlson P, Nilner K. All-ceramic fixed partial dentures designed according to the DC-Zircon technique. A 2-year clinical study. J Oral Rehabil 2005;32:180-7.

7. Raigrodski AJ, Chiche GJ, Potiket N, Hochstedler JL, Mohamed SE, Billiot S, Mercante DE. The efficacy of posterior three-unit zirconium-oxide-based ceramic fixed partial dental prostheses: a prospective clinical pilot study. J Prosthet Dent 2006;96:237-244. 
8. Sailer I, Fehér A, Filser F, Lüthy H, Gauckler LJ, Schärer P, Hämmerle CHF. Prospective clinical study of zirconia posterior fixed partial dentures: 3-year followup. Quintessence Int 2006;37:41-49.

9. Sailer I, Fehér A, Filser F, GaucklerLJ, Lüthy H, Hämmerle CHF. Five-Year clinical results of zirconia frameworks for posterior fixed partial dentures. Int $\mathrm{J}$ Prosthodont 2007;20:383-388.

10. Edelhoff D, Beuer F, Florian W, Johnen C. HIP zirconia fixed partial denturesclinical results after 3 years of clinical service. Quintessence Int 2008;39:459-471.

11. Schmitt J, Holst S, Wichmann M, Reich S, Gollner M, Hamel J. Zirconia posterior fixed partial dentures: a prospective clinical 3-year follow-up. Int J Prosthodont 2009;22:597-603.

12. Filser $F$, Kocher $P$, Weibel $F$, Lüthy $H$, Schärer $P$, Gauckler LJ. Reliability and strength of all-ceramic dental restaurations fabricated by direct ceramic machining (DCM). Int J Comp Dent 2001;4:89-106.

13. Fischer J, Stawarczyk B, Hämmerle $\mathrm{CH}$. Flexural strength of veneering ceramics for zirconia. J Dent 2008;36:316-321.

14. Voss R. Stability of metal-ceramic crowns (die Festigkeit metallkeramischer Kronen). Dtsch Zahnärztl Z 1969;24:726-731.

15. Wolf D, Bindl A, Schmidlin PR, Lüthy H, Mörmann WH. Strength of CAD/CAM generated esthetic ceramic molar implant crowns. Int J Oral Maxillofac Implants 2008;23:609-617.

16. Quinn JB, Quinn GD. A practical and systematic review of Weibull statistics for reporting strengths of dental materials. Dent Mater 2010;26:135-147. 
17. Kellerhoff R, Fischer J. In vitro fracture strength and thermal shock resistance of metal-ceramic crowns with cast and machined AuTi frameworks. J Prosthet Dent 2007;97:207-215.

18. Johnson NL, Kotz S, Balakrishnan N. Continuous Univariate Distributions. Volume 1. Second Edition. John Wiley \& Sons, Inc. 1994.

19. Hallinan AJ. A Review of the Weibull Distribution. Journal of Quality Technology 1993;25:85-93.

20. McCabe JF, Carrick TE. A statistical approach to the mechanical testing of dental materials. Dent Mater 1986;2:139-142.

21. Abernethy RB. The New Weibull Handbook. $5^{\text {th }}$ Edition, North Palm Beach, Florida, USA: Dr. Robert Abernethy, Publisher; 2009.

22. Wissenschaftliche Tabellen Geigy, Teilband Statistik, 8. Auflage, Basel, 1980 CIBA-GEIGY Limited, Basel, Switzerland.

23. Johnson CA. Fracture statistics of multiple flaw distributions. In Fracture Mechanics of Ceramics Vol. 5 Surface Flaws, Statistics, and Microcracking Eds. Bradt, R.C., Evans, A.G., Hasselman, D.P.H. and Lange, F.F. Plenum Press 1983.

24. Nelson, W. Applied Life Data Analysis. John Wiley \& Sons, Inc. 1982

25. International Standard: ISO 20501: 2003 (E) Fine ceramics (advanced ceramics, advanced technical ceramics)-Weibull statistics for strength data.

26. Silva NRFA, Bonfante EA, Zavanelli RA, Thompson VP, Ferencz JL, Coelho PG. Reliability of metalloceramic and zirconia-based ceramic crowns. J Dent Res 2010;89:1051-1056. 
27. Silva NRFA, Bonfante EA, Rafferty BT, Zavanelli RA, Rekow ED, Thompson VP, Ferencz JL, Coelho PG. Modified Y-TZP core design improves all-ceramic crowns reliability. J Dent Res 2011;90:104-108.

28. Coelho PG, Bonfante EA, Silva NRF, Rekow ED, Thompson VP. J Dent Res 2009;88:382-386.

29. Coelho PG, Silva NR, Bonfante EA, Guess PC, Rekow ED, Thompson VP. Fatique testing of two porcelain-zirconia all-ceramic crown systems. Dent Mater 2009;25:1122-1127. 


\section{Tables}

Table 1. Summary of products used.

Table 2. Firing schedules of veneering ceramic.

Table 3. Adjusted Anderson-Darling goodness-of-fit estimates for fracture load with failure type total fracture and failure type chipping under Normal and Weibull sampling assumptions. Note that smaller value of $A D$ means better fit.

Table 4. Estimates of the parameters of the Normal and Weibull distribution for the fracture load (complete data).

Table 5. Counts and relative frequencies and $95 \% \mathrm{Cl}$ for observed chipping of the veneering ceramic and total fractures of the veneering ceramics and zirconia framework occasions.

Table 6. Estimates of the parameters of the Normal and Weibull distribution for total fracture and chipping capital letters indicate differences for total fracture, small letters indicate differences chipping, nf stands for the number of failures and nc for the number of censored observations.

Table 7. Summary of all relevant results. 


\section{Figures}

Figure 1. Failure types: a) total fracture of veneering ceramic and zirconia framework b) chipping of veneering ceramic

Figure 2. Comparison of the Weibull and Normal densities: Weibull $m=8, s=1000$, Normal $\mu=942, \sigma=140$ (The expectation of the Weibull distribution is equal to the expectation of the Normal distribution. Moreover, the variance of both distributions is equal.).

Figure 3. Boxplots of fracture load with complete data assumption.

Figure 4. Probability plots for two different failure modes (total fracture and chipping) under Normal and Weibull assumption. 
Figure 1. Failure types: a) total fracture of veneering ceramic and zirconia framework b) chipping of veneering ceramic.

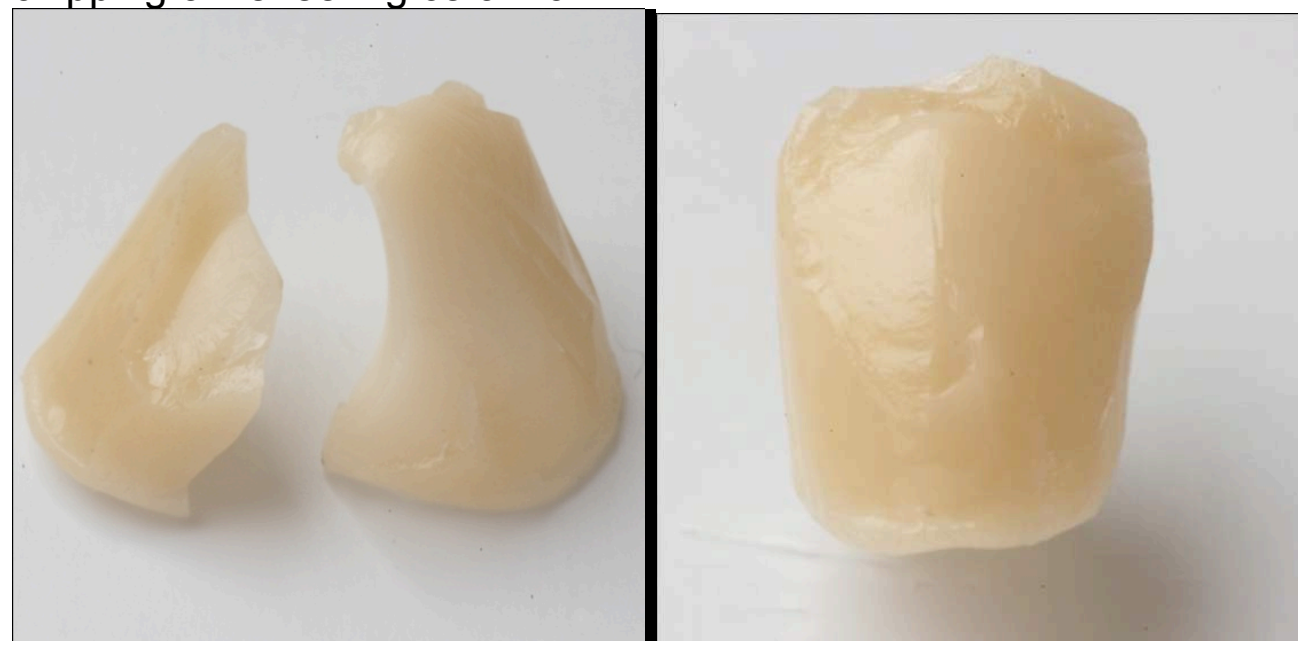


Figure 2. Comparison of the Weibull and Normal densities Weibull $m=8, s=1000$, Normal $\mu=942, \sigma=140$ (The expectation of the Weibull distribution is equal to the expectation of the Normal distribution. Moreover, the variance of both distributions is equal).

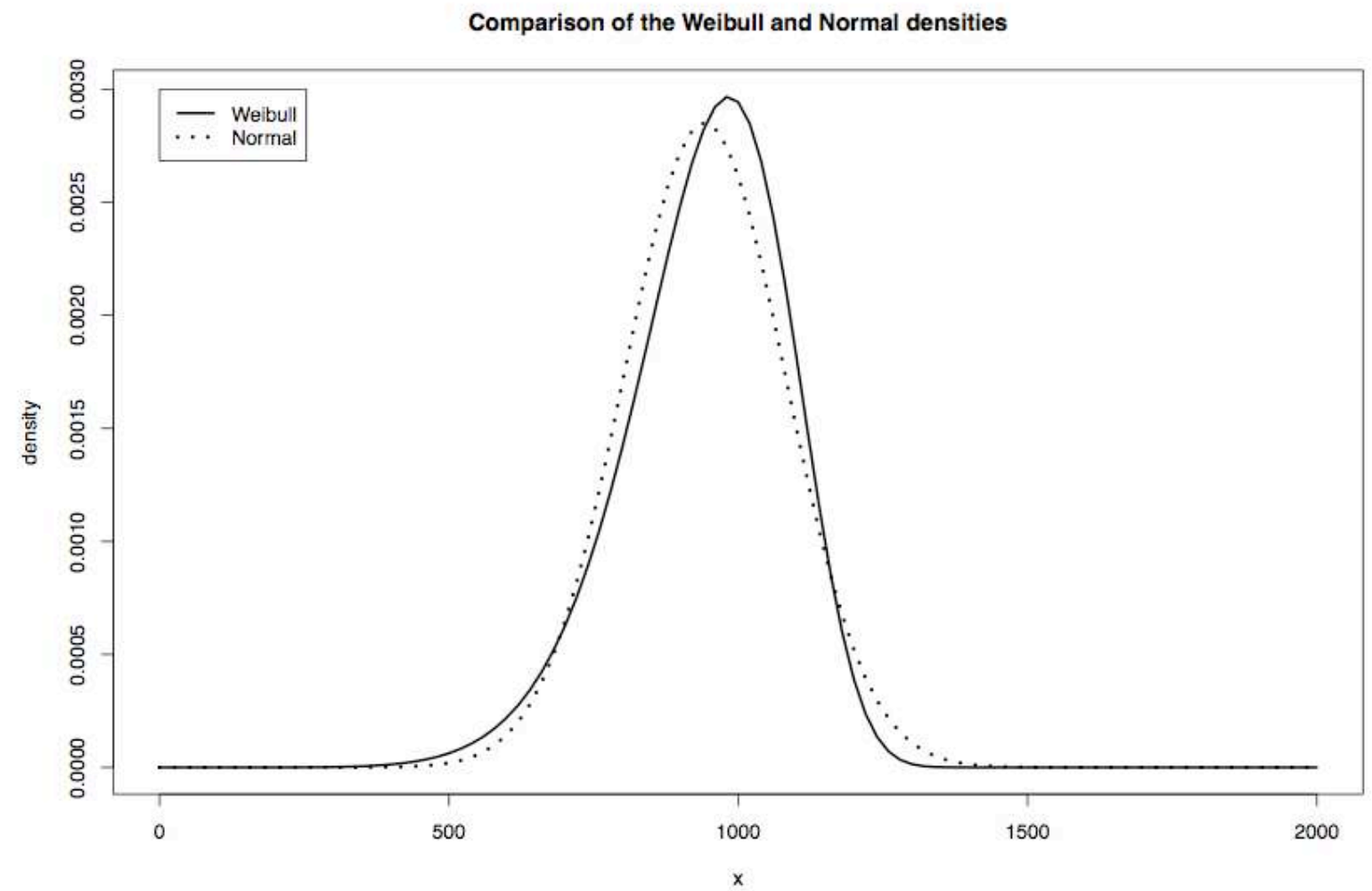


Figure 3. Boxplots of fracture load with complete data assumption.

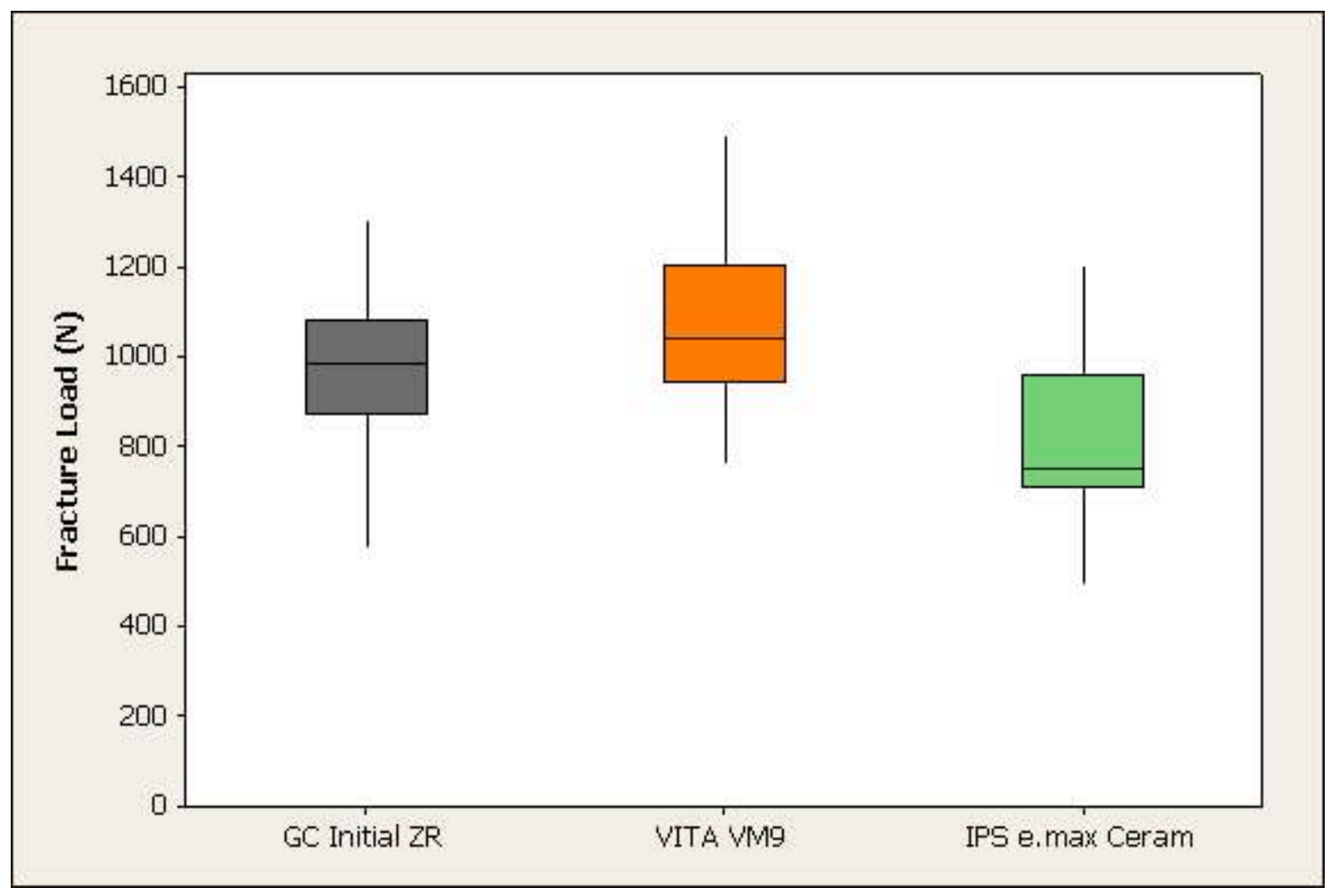


Figure 4. Probability plots for two different failure modes (total fracture and chipping) under Normal and Weibull assumption.

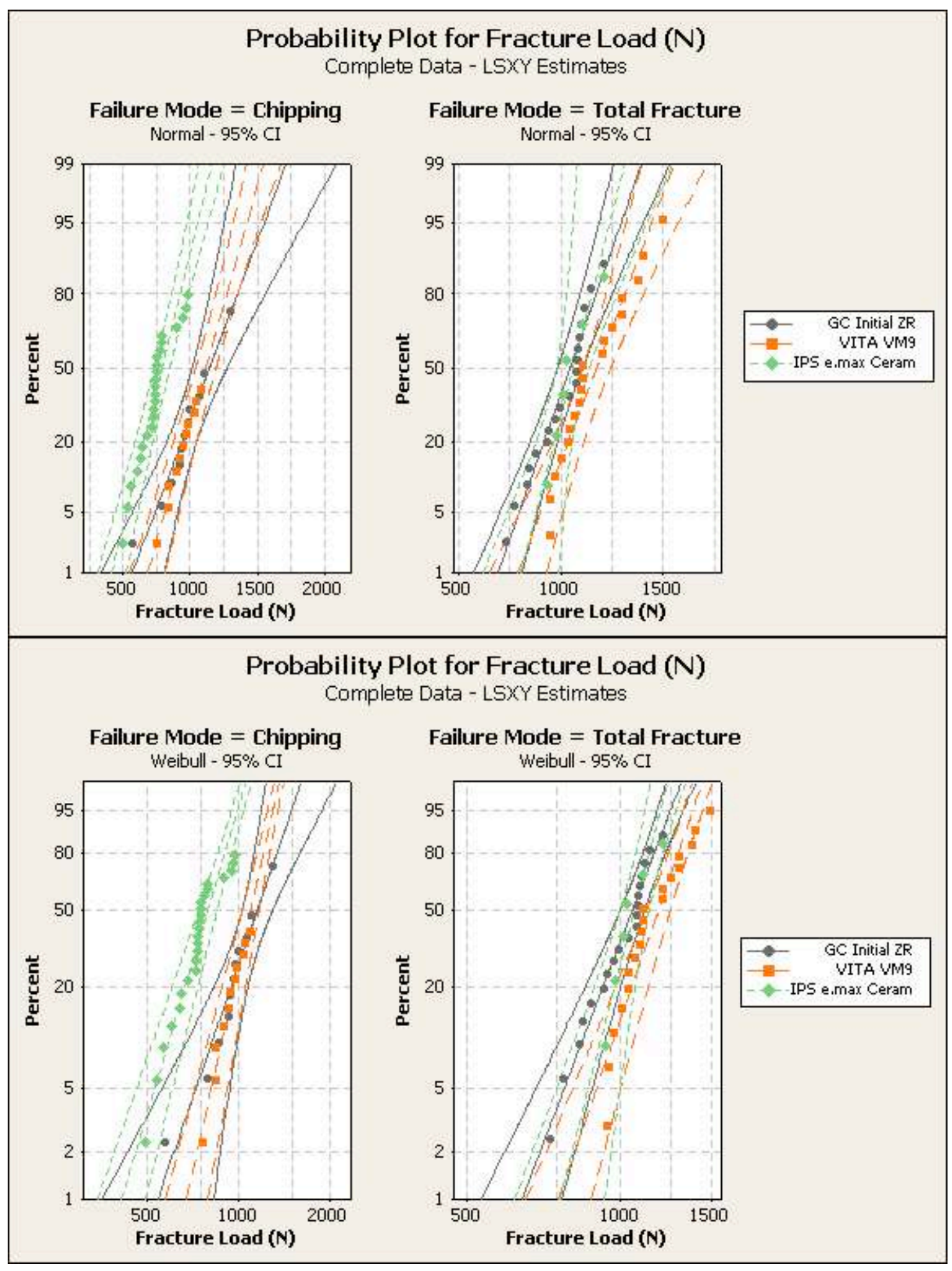


Table 1. Summary of products used.

\begin{tabular}{|l|l|l|l|}
\hline Ceramics & Name & Manufacturers & Batch.No. \\
\hline Framework & ZENO ZR & Wieland Dental, Pforzheim, Germany & $20070206-08$ \\
\hline \multirow{2}{*}{ Veneering ceramic } & GC Initail ZR & GC Europe, Leuven, Belgium & \\
\cline { 2 - 4 } & VITA VM9 & Vita Zahnfabrik, Bad Säckingen, Germany & 13340 \\
\cline { 2 - 4 } & IPS e.max Ceram & Ivoclar Vivadent, Schaan, Liechtenstein & L37100 \\
\hline
\end{tabular}


Table 2. Firing schedules of veneering ceramic.

\begin{tabular}{|l|l|l|l|l|l|}
\hline \multirow{2}{*}{$\begin{array}{l}\text { Veneering } \\
\text { ceramic }\end{array}$} & Pre Drying & $\begin{array}{l}\text { Heating } \\
\text { Rate } \\
\left({ }^{\circ} \mathrm{C} / \mathrm{min}\right)\end{array}$ & $\begin{array}{l}\text { Firing } \\
\text { Temperature } \\
\left({ }^{\circ} \mathrm{C}\right)\end{array}$ & $\begin{array}{l}\text { Holding } \\
\text { Time } \\
(\mathrm{min})\end{array}$ \\
\hline Liner (with Vacuum) & $\begin{array}{l}\text { Time } \\
(\mathrm{min})\end{array}$ & \multicolumn{5}{l|}{} \\
\hline GC Initial ZR & 450 & 4 & 55 & 810 & 1 \\
\hline Vita VM9 & 500 & 6 & 55 & 930 & 1 \\
\hline IPS e.max Ceram & 400 & 4 & 60 & 960 & 1 \\
\hline Dentin Firing (with vacuum) & 400 & 6 & 45 & 780 & 1 \\
\hline GC Initial ZR & 500 & 6 & 55 & 910 & 1 \\
\hline Vita VM9 & 4 & 50 & 750 & 1 \\
\hline IPS e.max Ceram & 400 & 4 & 75 & 785 \\
\hline Glaze Firing (all without vacuum, except IPS e.max Ceram) & 0 \\
\hline GC Initial ZR & 450 & 2 & 40 & 900 & 1 \\
\hline Vita VM9 & 500 & 0 & 60 & 725 & 1 \\
\hline IPS e.max Ceram & 400 & 6 &
\end{tabular}


Table 3. Adjusted Anderson-Darling goodness-of-fit estimates for fracture load with failure type total fracture and with failure type chipping under Normal and Weibull sampling assumptions. Note that smaller value of $A D$ means better fit.

\begin{tabular}{|l|l|l|l|}
\hline & AD (complete data) & AD (total fracture) & AD (chipping) \\
\hline GC Initial ZR: Normal & 0.750 & 6.6 & 18.2 \\
\hline GC Initial ZR: Weibull & 0.705 & 6.5 & 18.2 \\
\hline VITA VM9: Normal & 0.937 & 1.3 & 101.4 \\
\hline VITA VM9: Weibull & 1.937 & 2.2 & 101.4 \\
\hline IPS e.max Ceram: Normal & 1.111 & 3.5 & 25.1 \\
\hline IPS e.max Ceram: Weibull & 1.674 & 3.8 & 25.7 \\
\hline
\end{tabular}


Table 4. Estimates of the parameters of the Normal and Weibull distribution for the fracture load (complete data).

\begin{tabular}{|c|c|c|c|c|}
\hline \multicolumn{5}{|c|}{ Classic analysis method } \\
\hline & Mean (MPa) & $\begin{array}{l}95 \% \mathrm{Cl} \text { (mean) } \\
(\mathrm{MPa})\end{array}$ & SD (MPa) & $95 \% \mathrm{Cl}(\mathrm{SD}) \mathrm{MPa}$ \\
\hline GC Initial ZR & $978^{b}$ & $(922,1035)$ & $157^{\mathrm{a}}$ & $(119,205)$ \\
\hline VITA VM9 & $1074^{b}$ & $(1009,1139)$ & $179^{\mathrm{a}}$ & $(137,235)$ \\
\hline IPS e.max Ceram & $798^{\mathrm{a}}$ & $(735,861)$ & $174^{\mathrm{a}}$ & $(133,228)$ \\
\hline \multicolumn{5}{|c|}{ Weibull statistic } \\
\hline & scale & $95 \% \mathrm{Cl}($ scale) & shape & $95 \% \mathrm{Cl}($ scale) \\
\hline GC Initial ZR & $1043^{b}$ & $(989,1099)$ & $7.2^{\mathrm{a}}$ & $(5.3,9.7)$ \\
\hline VITA VM9 & $1139^{b}$ & $(1083,1198)$ & $7.8^{\mathrm{a}}$ & $(6.3,9.5)$ \\
\hline IPS e.max Ceram & $859^{\mathrm{a}}$ & $(804,919)$ & $5.8^{\mathrm{a}}$ & $(4.6,7.2)$ \\
\hline
\end{tabular}

Different letters a,b represent a significant difference according to post-hoc test between the levels of the test groups. 
Table 5. Counts and relative frequencies and $95 \% \mathrm{Cl}$ for observed chipping of the veneering ceramic and total fractures of the veneering ceramic and zirconia framework occasions.

\begin{tabular}{|l|l|l|l|l|}
\hline Test groups & $\mathrm{n}$ & $\begin{array}{l}\text { Count of } \\
\text { chipping }\end{array}$ & $\begin{array}{l}\text { Count of } \\
\text { total fracture }\end{array}$ & $\begin{array}{l}\text { Relative frequency } \\
\text { of total fracture and } \\
95 \% \mathrm{Cl}(\mathrm{p})\end{array}$ \\
\hline GC Initial ZR & 30 & 11 & 19 & $0.63(0.43,0.81)$ \\
\hline VITA VM9 & 30 & 11 & 19 & $0.63(0.43,0.81)$ \\
\hline IPS e.max Ceram & 30 & 24 & 6 & $0.20(0.07,0.39)$ \\
\hline
\end{tabular}


Table 6. Estimates of the parameters of the Normal and Weibull distribution for total fracture and chipping capital letters indicate differences for total fracture, small letters indicate differences chipping, nf stands for the number of failures and nc for the number of censored observations.

\begin{tabular}{|c|c|c|c|c|c|c|c|c|}
\hline & \multicolumn{4}{|c|}{ Classic analysis method } & \multicolumn{4}{|c|}{ Weibull statistic } \\
\hline & mean & $95 \% \mathrm{Cl}$ (mean) & SD & $95 \% \mathrm{Cl}(\mathrm{SD})$ & scale & $\begin{array}{l}95 \% \mathrm{Cl} \\
\text { (scale) }\end{array}$ & shape & $\begin{array}{l}95 \% \mathrm{Cl} \\
\text { (shape) }\end{array}$ \\
\hline $\begin{array}{l}\text { GC Initial ZR: total } \\
\text { fracture }(n f=19, n c=11)\end{array}$ & $1039^{A}$ & $(978,1101)$ & $152^{A}$ & $(110,210)$ & $1095^{\mathrm{A}}$ & $(1039,1153)$ & $8.5^{\mathrm{A}}$ & $(6.2,11.6)$ \\
\hline $\begin{array}{l}\text { VITA VM9: } \quad \text { total } \\
\text { fracture }(n f=19, n c=11)\end{array}$ & $1170^{B}$ & $(1099,1241)$ & $166^{A}$ & $(117,234)$ & $1228^{\mathrm{B}}$ & $(1169,1290)$ & $9.4^{\mathrm{A}}$ & $(7.3,12.1)$ \\
\hline $\begin{array}{l}\text { IPS e.max Ceram: total } \\
\text { fracture }(n f=6, n c=24)\end{array}$ & $1054^{A, B}$ & $(972,1135)$ & $110^{A}$ & $(51,237)$ & $1092^{A}$ & $(1026,1162)$ & $12.5^{\mathrm{A}}$ & $(7.5,20.7)$ \\
\hline $\begin{array}{l}\text { GC Initial ZR: chipping } \\
(n f=11, n c=19)\end{array}$ & $1145^{b}$ & $(1014,1275)$ & $247^{\mathrm{a}}$ & $(149,407)$ & $1231^{b}$ & $(1074,1412)$ & $5.6^{\mathrm{a}}$ & $(3.0,10.3)$ \\
\hline $\begin{array}{l}\text { VITA VM9: chipping } \\
(\mathrm{nf}=11, \mathrm{nc}=19)\end{array}$ & $1117^{b}$ & $(1041,1194)$ & $186^{\mathrm{a}}$ & $(145,238)$ & $1145^{b}$ & $(1080,1213)$ & $8.7^{\mathrm{a}}$ & $(7.0,10.8)$ \\
\hline $\begin{array}{l}\text { IPS e.max Ceram: } \\
\text { chipping }(\mathrm{nf}=24, \mathrm{nc}=6)\end{array}$ & $790^{a}$ & $(732,849)$ & $160^{\mathrm{a}}$ & $(128,200)$ & $836^{a}$ & $(784,892)$ & $6.5^{\mathrm{a}}$ & $(5.3,7.8)$ \\
\hline
\end{tabular}


Table 7. Summary of all relevant results.

\begin{tabular}{|c|c|c|c|c|c|}
\hline \multicolumn{6}{|c|}{ Study design } \\
\hline & & & & $\begin{array}{l}\text { Results of th } \\
\text { method }(N) \text { co } \\
\text { Weibull stati }\end{array}$ & $\begin{array}{l}\text { classic } \\
\text { pared to } \\
\text { ic }(\mathrm{W})\end{array}$ \\
\hline & $\begin{array}{l}\text { Veneered } \\
\text { with GC } \\
\text { Initial ZR }\end{array}$ & $\begin{array}{l}\text { Veneered } \\
\text { with Vita } \\
\text { VM9 }\end{array}$ & $\begin{array}{l}\text { Veneered with } \\
\text { IPS e.max } \\
\text { Ceram }\end{array}$ & $\begin{array}{l}\text { mean vs } \\
\text { characteristic } \\
\text { strength }\end{array}$ & $\begin{array}{l}\text { SD vs } \\
\text { modulus }\end{array}$ \\
\hline $\begin{array}{l}\text { Fracture load } \\
\text { (complete data) }\end{array}$ & $\begin{array}{l}N: b / a \\
W: b / a\end{array}$ & $\begin{array}{l}N: b / a \\
W: b / a\end{array}$ & $\begin{array}{l}\mathrm{N}: \mathrm{a} / \mathrm{a} \\
\mathrm{W}: \mathrm{a} / \mathrm{a}\end{array}$ & similar & similar \\
\hline Total fracture & $\begin{array}{l}\mathrm{N}: \mathrm{A} / \mathrm{A} \\
\mathrm{W}: \mathrm{A} / \mathrm{A}\end{array}$ & $\begin{array}{l}\mathrm{N}: \mathrm{B} / \mathrm{A} \\
\mathrm{W}: \mathrm{B} / \mathrm{A}\end{array}$ & $\begin{array}{l}N: A, B / A \\
W: A / A\end{array}$ & slightly different & similar \\
\hline Chipping & $\begin{array}{l}N: b / a \\
W: b / a\end{array}$ & $\begin{array}{l}N: b / a \\
W: b / a\end{array}$ & $\begin{array}{l}\mathrm{N}: \mathrm{a} / \mathrm{a} \\
\mathrm{W}: \mathrm{a} / \mathrm{a}\end{array}$ & similar & similar \\
\hline $\begin{array}{l}\text { Results complete data } \\
\text { assumption compared to } \\
\text { uncensored/censored }\end{array}$ & different & different & similar & & \\
\hline
\end{tabular}

$\mathrm{x} / \mathrm{y}$ : First parameter of the distribution (mean or characteristic strength) / Second parameter of the distribution (SD or modulus) 